\title{
Genetic DiversityAssessment in Ten Aromatic Rice Varieties of Bangladesh
}

\author{
Tahmina Islam, Shinthia Rahman, M. Imdadul Hoque and \\ R. H. Sarker
}

Plant Breeding and Biotechnology Laboratory, Department of Botany, University of Dhaka, Dhaka-1000, Bangladesh

Key words: Aromatic rice, Genetic variability, Molecular marker, Cluster analysis

\begin{abstract}
The availability of molecular marker systems allowed estimating the relationships among various taxa. This study was aimed at assessing the genetic diversity among ten aromatic rice (Oryza sativa L.) pools from Bangladesh by means of randomly amplified polymorphic DNA (RAPD) markers. These varieties were evaluated for polymorphisms after amplification with 10 decamer primers. A total of 60 RAPD fragments were generated among the assessed varieties with a polymorphism percentage of 80 . Cluster analysis by the unweighted pair group method of arithmetic means (UPGMA) showed that these 10 varieties could be placed into two groups with a similarity ranging from 65 to $86 \%$ depicting adjacent association between Rajbhog and Kalijira-12, whereas Maloti belongs to a separate group maintaining maximum distance from rest of the varieties. The analysis revealed that the intervarietal genetic relationship of several varieties is related to their center of origin. As expected, most of the varieties have a narrow genetic base. The present results could be used for the selection of possible parents to generate a mapping population and utilized by the breeders for assessing the genetic diversity of rice genotypes.
\end{abstract}

\section{Introduction}

DNA marker technology has widened up a new era to facilitate the analysis of plant genetic diversity and resource conservation. Molecular markers usually reveal variances at DNA level, which is more reliable as compared to morphological analysis because many characters of interest have low heritability and are genetically complex. Molecular markers provide information that helps in deciding the distinctiveness of species and their ranking according to the number of close relatives and phylogenetic position (Rahman et al. 2007). Several 
types of molecular markers are available for evaluating the extent of genetic variation in rice. These include RFLP (Botstein et al. 1980), RAPD (Williams et al. 1990), AFLP (Vos et al. 1995) and SSR (Tautz 1989). Among these molecular markers RAPD is increasingly being employed in genetic research owing to its speedy process and simplicity (Williams et al. 1990). This technique allows the examination of genomic variation without prior knowledge of DNA sequences (Hadrys et al. 1992). Thus this is specially useful for unzipping the variations in species with low genetic variability when other techniques such as isozyme analysis fails to reveal differences among the individuals (Kiani 2011). Moreover, commercially important crops can be unambiguously grouped on the basis of their varietal distinctiveness and relativeness by RAPD fingerprinting (Thomas et al. 2006). RAPD markers are considered to be unbiased and neutral markers for genetic mapping applications (Michelmore et al. 1991), population genetics (Haig et al. 1994) and taxonomy (Chapco et al. 1992) as well as for genetic diagnostics. RAPD has been used for classifying and assessing diversity, relatedness of rice genotypes by several groups (Porreca et al. 2001, Rabbani et al. 2008). Although, Bangladesh is known for its rich diversity of aromatic rice varieties, very limited numbers of aromatic rice germplasms/breeding lines are being used repeatedly in the specific improvement program. Hence, an important source for the introduction of new traits is the existence of a genetically diverse pool of rice germplasm available in the country but still lying unexplored. This study aimed at using RAPD markers to evaluate the genetic variation within a collection of aromatic rice varieties and to reveal genetic relationships among them for future use in selection, hybridization, biodiversity assessment and conservation of diverse gene pools.

\section{Materials and Methods}

A total of 10 aromatic rice varieties viz., namely Kalguchi, Kaminisoru, Maloti, Tilkapur, Doairgura, Chinigura-2, Rajbhog, Kalijira-12, Premful and Sorukamini collected from Bangabandhu Sheikh Mujibur Rahman Agricultural University, Gazipur, Bangladesh were used for this investigation. The plants were raised in the Botanical Garden of the Department of Botany, University of Dhaka. These varieties were distinctly different from each other in respect of their origin. To perform RAPD analysis, young growing tillers were collected randomly from each cultivar and fresh leaves from each tiller were used for isolation of genomic DNA.

Extraction of Genomic DNA: For the extraction of genomic DNA cetyltrimethyl ammonium bromide (CTAB) method (Doyle and Doyle 1990) was used with some modifications. Young and fresh leaves collected from 15 days old seedlings 
were used for this purpose. Leaves were first washed in distilled water and then with ethanol to remove spores of microorganisms and any other source of foreign DNA. They were then dried using fresh tissue paper. $100 \mathrm{mg}$ leaf tissue were taken in liquid nitrogen and grinded to fine powder followed by addition of $1.6 \mathrm{ml}$ extraction buffer ( $3 \% \mathrm{CTAB}, 1.4 \mathrm{M} \mathrm{NaCl}, 100 \mathrm{mMTris}-\mathrm{HCl}, \mathrm{pH} 8.0,20$ $\mathrm{mM}$ EDTA, $\mathrm{pH} 8.0$ and $0.2 \%$ mercaptoethanol). The homogenous paste then transferred to an Eppendorf tube $(2.0 \mathrm{ml})$ and incubated at $60^{\circ} \mathrm{C}$ in a water bath for $30 \mathrm{~min}$. The samples were centrifuged at $13,000 \mathrm{rpm}$ for $10 \mathrm{~min}$ at $4^{\circ} \mathrm{C}$ then equal volume of phenol : chloroform : isoamyl alcohol $(25: 24: 1)$ was added with the supernatants and centrifuged the tubes at 13,000 rpm for $10 \mathrm{~min}$. The supernatant with $2 / 3$ volume chilled isopropanol was kept for overnight at $-20^{\circ} \mathrm{C}$ to precipitate the DNA. The supernatants were discarded carefully after centrifugation for $10 \mathrm{~min}$ at 13,000 rpm and DNA pellet was collected. The pellet was washed with $70 \%$ ice-cold ethanol and air dried. The dried DNA was dissolved in $50 \mu \mathrm{l}$ of TE buffer and treated with RNase A for $30 \mathrm{~min}$ at $37^{\circ} \mathrm{C}$ and store at $-20^{\circ} \mathrm{C}$. The concentration of DNA was estimated with nanodrop.

DNA amplification and gel electrophoresis: Ten primers of arbitrary sequence were tested. List of the primers that showed a reproducible amplification pattern is shown in Table 1. Oligonucleotide primers had $60-70 \%$ of $(\mathrm{G}+\mathrm{C})$ content and were 10 nucleotides long. The following protocol was used for PCR amplification: $25 \mu \mathrm{l}$ reaction mixture contains $2.5 \mu \mathrm{l} 10 \times$ Taq DNA buffer, $100 \mu \mathrm{M}$ dNTPs, $1 \mu \mathrm{M}$ primer, $1 \mathrm{U}$ Taq polymerase (Thermo-scientific) and $50 \mathrm{ng}$ genomic DNA. PCR mixture maintained at $4^{\circ} \mathrm{C}$ during its preparation. The PCR amplification mixture placed in a thermal cycler (Applied Biosystems) with the following thermal cycling conditions, these were one cycle of $94^{\circ} \mathrm{C}$ for $5 \mathrm{~min}, 30$ cycles of $94^{\circ} \mathrm{C}$ for $45 \mathrm{sec}, 32$ to $34^{\circ} \mathrm{C}$ for $30 \mathrm{sec}$ and $72^{\circ} \mathrm{C}$ for $3 \mathrm{~min}$ then one cycle of $72^{\circ} \mathrm{C}$ for $7 \mathrm{~min}$. After completion of cycling program, the reactions were held at $4^{\circ} \mathrm{C}$.

The amplification products were loaded on $2 \%$ agarose gel in tris-acetic acidEDTA (TAE) buffer and run in this buffer for at least 2 hrs and $30 \mathrm{~min}$ at 90 100V. PCR reactions were repeated at least twice for each cultivar on a first DNA extract to establish reproducibility of results. The results were confirmed using a different DNA extract of the same cultivar. Amplified products were scored as presence or absence of bands for each of the 10 cultivars with the 10 primers, faint bands were ignored.

Distance estimation: The bands observed in different lanes were designated a, $\mathrm{b}, \mathrm{c}, \mathrm{d}$ and so on and scored visually. Mostly dark and prominent bands were scored, although bands of lower intensity but with high reproducibility were included for analysis. The presence of a particular DNA band was scored as "1" 
and its absence as " 0 " for each of the primers considered. These data were used to calculate a distance matrix between genotypes according to Nei (1972). The distance matrix represents the fraction of shared DNA fragments between two samples. It ranges from zero to one, corresponding to complete genetic identity. We used the clustering program 'Popgene' program (https://sites.ualberta.ca / fyeh/popgene.html) to group the genotypes by the unweighted pair group method using arithmetic average (UPGMA). Genetic relationships among the tested samples were presented as a tree.

\section{Results and Discussion}

The significance of plant germplasm collection and preservation has increased due to genetic erosion and habitat destruction by modern agriculture. Many countries like Bangladesh, the landraces carrying a vast amount of genetic diversity were distributed in remote villages. But the number of landraces began to decline when high-yielding varieties were introduced. Most of the old landraces are now available in certain gene banks only, not in the hands of farmers. It is essential to rationalize conservation and use of genetic resources to guide in the establishment of strategies that ensure the maintenance of genetic variability, essential in plant breeding.

In the present investigation, RAPD markers were employed to assess the genetic diversity among 10 aromatic varieties of rice from Bangladesh. Although the use of molecular markers to study the genetic diversity and relationships among the different cultivars has been reported earlier (Porreca et al. 2001, Neeraja et al. 2002, Saker et al. 2005), the information on the genetic relationship between Bangladeshi aromatic rice varieties is limited. The results of present study indicated a considerable level of genetic variation in the cultivars. RAPD analysis usually used for the molecular typing of genetic variability. RAPD requires no prior sequence information for the fingerprinting of cultivar genomes and it has been used extensively for estimating genetic variations at the population level and among closely related species. Each step of this technique must be optimised to ensure its reproducibility due to its sensitivity towards experimental conditions. In the present investigation, we first optimized that the DNA extracted from the 10 rice varieties could be amplified by using OPA-1 and OPA-2 primers (Table 1). RAPD analysis was then performed using 10 primers. Amplified products were scored as presence or absence of bands and the polymorphisms were detected as differences in banding patterns on an agarose gel. Amplification was carried out twice to check their reproducibility. Only the primers that yielded reproducible patterns were considered for analysis (Table 1). Occasionally, the intensity of some bands was slightly reduced or increased 
but the total number of bands obtained with a primer remained the same. A negative control without the rice DNA template was performed for each primer. No amplification products were detected in this control. To verify that RAPDPCR produced reliable amplification patterns, PCR reactions were carried out on different extracts of the same varieties, and the same bands were always obtained. These confirmed the high reproducibility of the data.

Table 1. RAPD primers scored to draw the phylogenetic relationships between ten aromatic rice varieties.

\begin{tabular}{llccc}
\hline $\begin{array}{l}\text { Marker } \\
\text { ID }\end{array}$ & $\begin{array}{l}\text { Sequence } \\
\left(5^{\prime}-3^{\prime}\right)\end{array}$ & $\begin{array}{c}\text { Total no. } \\
\text { of RAPD } \\
\text { loci }\end{array}$ & $\begin{array}{c}\text { No. of } \\
\text { polymorphic } \\
\text { RAPD loci }\end{array}$ & $\begin{array}{c}\text { Percentage of } \\
\text { polymorphism }\end{array}$ \\
\hline OPA01 & TGC CGA GCT C & 6 & 5 & 83.33 \\
OPA02 & TGC CGA GCT G & 8 & 8 & 100 \\
OPA03 & AGT CAG CCA C & 7 & 7 & 100 \\
OPA04 & AAT CGG GCT G & 5 & 5 & 100 \\
OPA05 & AGG GGT CTT G & 6 & 5 & 83.33 \\
OPA06 & GGT CCC TGA C & 5 & 5 & 100 \\
OPA07 & GAA ACG GGT G & 8 & 8 & 100 \\
OPA08 & GTG ACG TAG G & 5 & 5 & 100 \\
OPA09 & GTG ATC GCA G & 4 & 4 & 100 \\
OPA10 & GTG ATC GCA G & 6 & 6 & \\
\hline
\end{tabular}

A total of 60 reproducible amplification products were generated across 10 varieties using 10 primers. Table 1 represents the 10 primers and the rate of polymorphic DNA fragments. Each primer produced between 4 to 8 bands. For one or more cultivars, $48 / 60$ bands $(80 \%)$ were polymorphic. The OPA2 and OPA8 primers amplified the maximum number of bands, and OPA9 primer resulted in the lowest number of fragments. The most useful primers for polymorphism detection and identification of cultivars were OPA1 and OPA8. These gave unique pattern in two varieties out of the 10 analysed samples (Fig. 1).

The amplification patterns of the 10 primers were used to derive the genetic relationships among analysed varieties. Genetic distances estimated with Nei coefficient and were plotted into a binary matrix. The samples showed an NL distance index varying from 0.79 (maximum value) for Maloti versus Doairgura and Maloti versus Premful to the minimum value of 0.069 for Kalijira-12 versus Rajbhog (Table 2). Maloti had the highest distance index value, suggesting that it was the most genetically distant sample among the 10 analysed varieties. 
Genetic correlations among the 10 cultivars revealed by UPGMA cluster analysis are shown in Fig. 2. The dendrogram was constructed using the distance index reported in Table 2. It shows two major groups (Cluster-1 and Cluster-2) of closely related samples that excluded the variety Maloti. Cluster-1 and Cluster-2 include Kalguchi, Kaminisoru, Doairgura, Tilkapur, Chinigura and Rajbhog, Kalijira-12, Premful, Sorukamini, respectively. Cluster-1 samples showed a higher genetic variability where Tilkapur and Chinigura showed lowest genetic variability (0.18) and Kalguchi and Chinigura resulted into highly genetically distance (0.33). On the other hand, Cluster-2 samples had a low genetic variability, the distance coefficient ranges from 0.069 to 0.16 . This result confirms the low variability among these rice varieties. The remaining one variety Maloti differ from both the major clusters. This result concluded with the different divergent origin and could be considered the distant relative of the analyzed varieties.

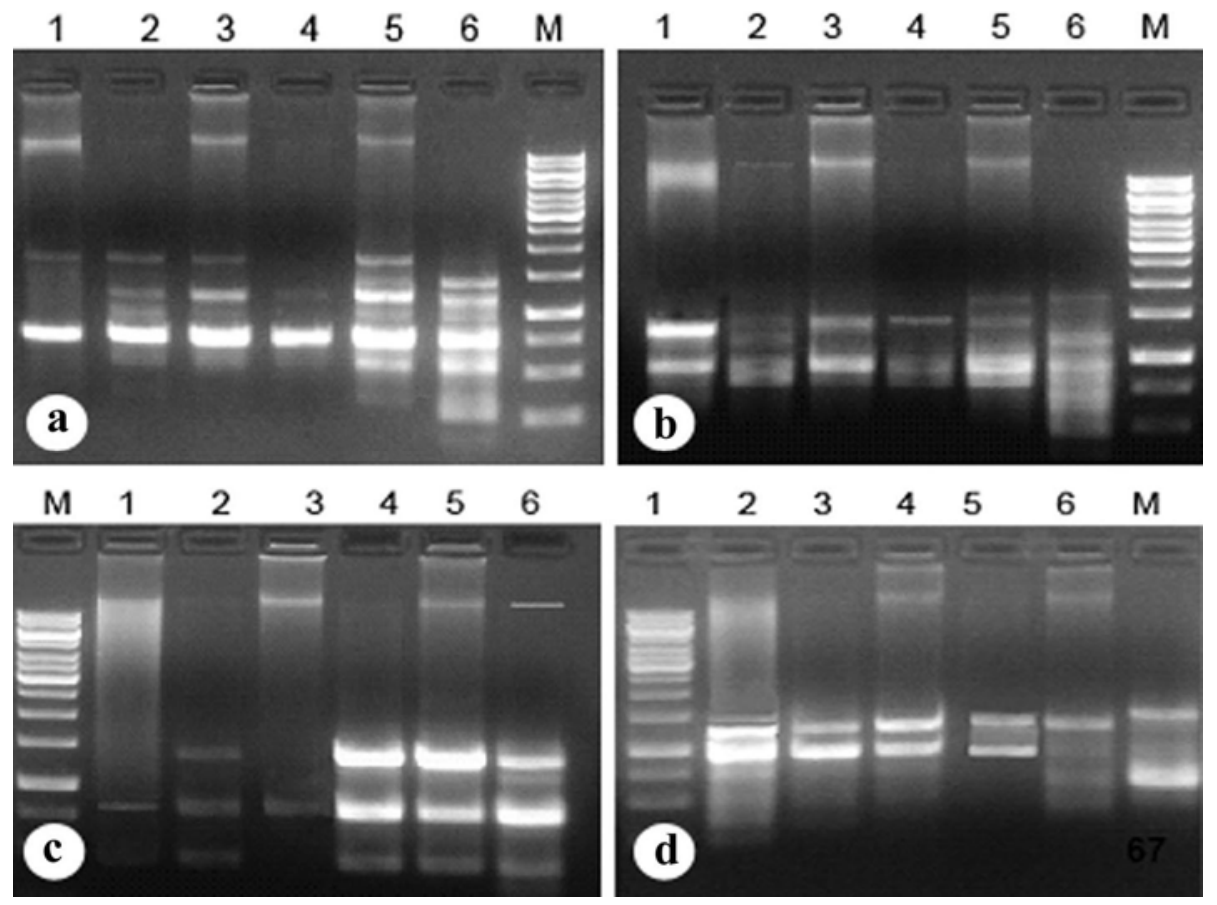

Fig. 1. RAPD profile of six representative aromatic rice varieties obtained with the primer OPA1 (a), OPA3 (b), OPA9 (c) and OPA10 (d), respectively. Lane- M. 1 Kb Marker, Lane 1-6. Amplified DNA of Kalguchi, Kaminisoru, Doairgura, Tilkapur, Chinigura and Maloti, respectively.

Present RAPD molecular typing of 10 aromatic rice varieties of Bangladesh indicates a high level of genetic variation with $80 \%$ of bands being polymorphic. Similar level of divergence from eight natural O. rufipogon from China and Brazil 
(82.1\% of polymorphism in a sample of 95 RAPD fragments) was reported earlier by Ge et al. 1999. These studies indicate that RAPDs are sufficiently informative and powerful tool to assess genetic variability of plants and prove its necessity towards future deign of collection strategies for germplasm conservation. Since, the dendrogram was constructed based on the RAPD markers, which showed that $80 \%$ of the bands observed were polymorphic between the ten rice varieties. This seems to be relatively high when compared to the reports of other RAPD studies, e.g. in Brassica spp. Alternaria spp., sorghum, alfalfa, celery and sweet potato. One of the reasons for this high level of polymorphism could be that the

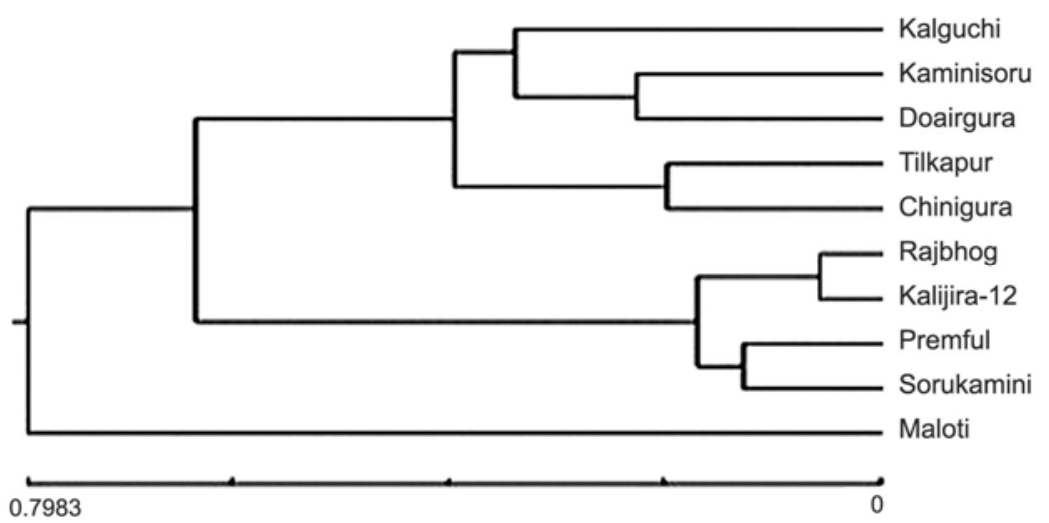

Fig. 2. Tree diagram for 10 aromatic rice varieties of Bangladesh based on unweighted pair group of arithmetic mean (UPGMA).

Table 2. Summary of Nei's (1972) genetic distances in ten aromatic rice varieties.

\begin{tabular}{|c|c|c|c|c|c|c|c|c|c|c|}
\hline & Kalguchi & $\begin{array}{l}\text { Kamini- } \\
\text { soru }\end{array}$ & $\begin{array}{l}\text { Doair- } \\
\text { gura }\end{array}$ & $\begin{array}{l}\text { Tilka- } \\
\text { pur }\end{array}$ & $\begin{array}{l}\text { Chini- } \\
\text { gura }\end{array}$ & Maloti & $\begin{array}{l}\text { Raj- } \\
\text { bhog }\end{array}$ & $\begin{array}{l}\text { Kalijira- } \\
12 \\
\end{array}$ & $\begin{array}{l}\text { Prem- } \\
\text { ful }\end{array}$ & $\begin{array}{l}\text { Soru- } \\
\text { kamini }\end{array}$ \\
\hline Kalguchi & 0 & & & & & & & & & \\
\hline Kaminisoru & 0.3102 & 0 & & & & & & & & \\
\hline Doairgura & 0.2877 & 0.2025 & 0 & & & & & & & \\
\hline Tilkapur & 0.2877 & 0.3808 & 0.3567 & 0 & & & & & & \\
\hline Chinigura & 0.3331 & 0.3808 & 0.3567 & 0.1823 & 0 & & & & & \\
\hline Maloti & 0.7621 & 0.6931 & 0.7985 & 0.6604 & 0.5390 & 0 & & & & \\
\hline Rajbhog & 0.5680 & 0.5108 & 0.4834 & 0.4834 & 0.5390 & 0.5680 & 0 & & & \\
\hline Kalijira-12 & 0.5680 & 0.6286 & 0.5390 & 0.5390 & 0.5978 & 0.6286 & 0.0690 & 0 & & \\
\hline Premful & 0.5390 & 0.6604 & 0.5680 & 0.5108 & 0.5680 & 0.7985 & 0.1625 & 0.1625 & 0 & \\
\hline Sorukamini & 0.5390 & 0.6604 & 0.5108 & 0.5108 & 0.5680 & 0.7270 & 0.1625 & 0.1625 & 0.1431 & 0 \\
\hline
\end{tabular}

intraspecific variation in rice is extensive. The other reason could be that primers with 60 to $70 \%$ GC content were used in the present study, whereas some other workers, including Yamamoto et al. (1994) have included primers with less GC 
content in their studies. Fukuoka et al. (1992) observed an increase in the number of bands with increasing GC content of the primers.

In conclusion, our current investigation revealed the genetic diversity between important aromatic rice varieties of Bangladesh - Kalguchi, Kaminisoru, Doairgura, Tilkapur, Chinigura, Maloti, Rajbhog, Kalijira-12, Premful and Sorukamini. Present study revealed that PCR based fingerprinting technique, RAPD was informative for estimating the extent of genetic diversity as well as determining the genetic relationship between different species. In future, our research work might be useful for cheap and easy RAPD analysis of new genetic species diversity.

\section{References}

Botstein D, White RL, Skolnick M and Davis RW (1980) Construction of genetic linkage map in man using restriction length polymorphisms. Amer. J. Hum. Genet. 32: 314331.

Chapco W, Ashton NW, Martel RK, Antonishishyn N and Crosby WL (1992) A feasibility study of the use of random amplified polymorphic DNA in the population genetics and systemic of grasshoppers. Genome 35: 569-574.

Doyle JJ and Doyle JL (1990) Isolation of plant DNA from fresh tissue. Focus 12:13-15.

Fukuoka S, Hosaka K and Kamijima O (1992) Use of random amplified polymorphic DNAs (RAPDs) for identification of rice accessions. Jpn. J. Genet. 67: 243-252.

Ge S, Oliveira GC, Schaal BA, Gao LZ and Hong DY (1999) RAPD variation within and between natural populations of the wild rice Oryzarufipogon from China and Brazil. Heredity 82: 638-644.

Hadrys H,Balick M and Schierwater B (1992) Application of random amplified polymorphic DNA (RAPD) in molecular ecology. Mol. Ecol. 1: 55-63.

Haig SM, Rhymer JM and Heckel DG(1994) Population differentiation in randomly amplified polymorphic DNA of red-cockaded woodpeckers Picoides borealis. Mol. Ecol. 3: 581-595.

Kiani G (2011) Genetic diversity analysis of iranian improved rice cultivars through RAPD markers. Not. Sci. Biol. 3: 135-139.

Michelmore RW, Paran I and Kesseli RV (1991) Identification of markers linked to disease-resistance genes by bulked segregant analysis: A rapid method to detect markers in specific genomic regions by using segregating populations. Proc Nat. Acad. Sci. USA 88: 9828-9832.

Nei M (1972).Genetic distance between populations. Am. Nat. 106: 283-292.

Porreca P, Sabina MR, Martelli G, Sunseri F, Greco I, Pruneddu G and Spanu A (2001) Genetic variability among Italian rice (Oryza sativa L.) cultivars investigated by RAPDs analysis. J. Genet. Breed. 55: 349-355. 
Rabbani MA, Pervaiz ZH and Masood MS (2008) Genetic diversity analysis of traditional and improved cultivars of Pakistani rice (Oryza sativa L.) using RAPD markers. Electron J. Biotechnol. 11: 1-10.

Rahman SN, Islam MDS Alam MDS and Nasiruddin KM (2007) Genetic polymorphism in rice (Oryza sativa L.) through RAPD analysis. Indian J. Biotechnol. 6: 224-229.

Tautz D (1989) Hypervariablity of simple sequences as a general source of polymorphic DNA markers. Nucleic Acids Res. 17:6463-6471.

Thomas G, Mohapatra T, Rao AR and Sharma RP (2006) Distinguishing Indian commercial wheat varieties using RAPD based DNA fingerprints. Indian Biotechnol. 5: 200-206.

Vos P, Hogers R, Bleeker M, Reijans M, Van de Lee T, Hornes M, Frijters A, Pot J, Peleman J and Kuiper M (1995) AFLP: A new technique for DNA fingerprinting. Nucleic Acids Res. 23: 4407-4414.

Williams JGK, Kubelik AR, Livak KJ, Rafalski JA and Scott VT (1990) DNA polymorphisms amplified by arbitrary primers are useful as genetic markers. Nucleic Acids Res. 18: 6531- 6535.

Yamamoto K, Quelle FW, Thierfelder WE, Kreider BL, Gilbert DJ, Jenkins NA, Copeland NG, Silvennoinen O and Ihle JN (1994) Stat4, a novel gamma interferon activation site-binding protein expressed in early myeloid differentiation. Mol. Cell Biol. 14: 4342-4349.

Neerja CN, Sarla N and Siddique EA (2002) RAPD analysis of genetic diversity in Indian landraces of rice (Oryza sativa L). J. Plant Biochemistry and Biotechnol. 11: 93-97.

Sarker MM, Youseff SS, Abdullah NA, Bashandy HS and El-Sharkawy AM (2005) Genetic analysis of some Egyptian rice genotypes using RAPD, SSR and AFLP. African J. Biotechnol. 4(9): 882-890. 